\title{
Mechanical and Viscoelastic Properties of Soybean Oil Thermoset Reinforced with Jute Fabrics and Carded Lyocell Fiber
}

\author{
Kayode Adekunle, ${ }^{1}$ Christian Patzelt, ${ }^{2}$ Adib Kalantar, ${ }^{1}$ Mikael Skrifvars ${ }^{1}$ \\ ${ }^{1}$ School of Engineering, University of Borås, SE-501 90 Borås, Sweden \\ ${ }^{2}$ Automotive Engineering, University of Applied Sciences, Westsächsische Hochschule Zwickau, 08012 Zwickau, \\ Germany
}

Received 16 August 2010; accepted 18 February 2011

DOI 10.1002/app.34360

Published online 29 June 2011 in Wiley Online Library (wileyonlinelibrary.com).

\begin{abstract}
Composites and hybrid composites were manufactured from renewable materials based on jute fibers, regenerated cellulose fibers (Lyocell), and thermosetting polymer from soybean oil. Three different types of jute fabrics with biaxial weave architecture but different surface weights, and carded Lyocell fiber were used as reinforcements. Hybrid composites were also manufactured by combining the jute reinforcements with the Lyocell. The Lyocell composite was found to have better mechanical properties than other composites. It has tensile strength and modulus of about $144 \mathrm{MPa}$ and $18 \mathrm{GPa}$, respectively. The jute composites also have relatively good mechanical properties, as their tensile strengths and moduli were found to be between 65 and $84 \mathrm{MPa}$, and
\end{abstract}

between 14 and $19 \mathrm{GPa}$, respectively. The Lyocell-reinforced composite showed the highest flexural strength and modulus, of about $217 \mathrm{MPa}$ and $13 \mathrm{GPa}$, respectively. In all cases, the hybrid composites in this study showed improved mechanical properties but lower storage modulus. The Lyocell fiber gave the highest impact strength of about $35 \mathrm{~kJ} / \mathrm{m}^{2}$, which could be a result of its morphology. Dynamic mechanical analysis showed that the Lyocell reinforced composite has the best viscoelastic properties. ( 2011 Wiley Periodicals, Inc. J Appl Polym Sci 122: 2855-2863, 2011

Key words: mechanical properties; renewable resources; impact resistance; biofibers; thermosets

\section{INTRODUCTION}

Renewable materials are being sought after due to the fact that they are sustainable and environmental friendly. Government policy on reducing the emission of greenhouse gases is the main drive toward sustainability. Many researchers are working on biobased materials to improve the mechanical properties and to possibly discover a wider range of applications.

There have been many reports on the reinforcement of biodegradable thermoplastics with natural/ plant-based fibers. ${ }^{1-5}$ Preparation and characterization of biocomposite materials from natural fibers and natural matrices has been reported by Takahashi et al., ${ }^{6}$ Alix et al., ${ }^{7}$ and Tran et al. ${ }^{8}$ A comprehensive review of biofibers and biocomposites has also been published by John and Thomas. ${ }^{9}$ Carrillo et al. ${ }^{10}$ reported the properties of a conventional thermoplastic reinforced with Lyocell fiber; also, hybrid composites of jute and man-made cellulose fiber with polypropylene have been reported by

Correspondence to: K. Adekunle (kayode.adekunle@hb.se).

Journal of Applied Polymer Science, Vol. 122, 2855-2863 (2011) (C) 2011 Wiley Periodicals, Inc.
Khan et al., ${ }^{11}$ but quite little has been reported on hybrid woven fabric/Lyocell fiber-reinforced biobased thermosetting polymers.

Textile-reinforced composites based on natural fibers have been studied by many research groups in recent years due to their good mechanical performance, excellent drape ability, easy handling, excellent integrity, conformability for advanced structural applications, and reduced manufacturing cost. ${ }^{12}$ Woven fabrics have been found to be better than nonwoven fibers as reinforcements, because the weave architectures of woven fabrics affect the permeability, and the mechanical and fracture properties of the composite. ${ }^{12}$ On the other hand, nonwoven mats with aligned fibers are of interest as they have no crimp and are of low cost. Textile structural composites are finding use in various high-performance applications. ${ }^{13}$ Bledzki and Zhang ${ }^{14}$ have reported the use of jute fabrics as reinforcement in the preparation of composites. Different cellulose fibers have been studied by many researchers as reinforcement in various matrices. ${ }^{15,16}$ The mechanical properties of jute-woven fabric-reinforced polyester composites have been studied by Munikenche et al. ${ }^{17}$ and Ahmed and Vijayarangan $^{18,19}$ and Wambua et al. ${ }^{20}$ also discussed the properties of flax, hemp, and jute fabric-reinforced 


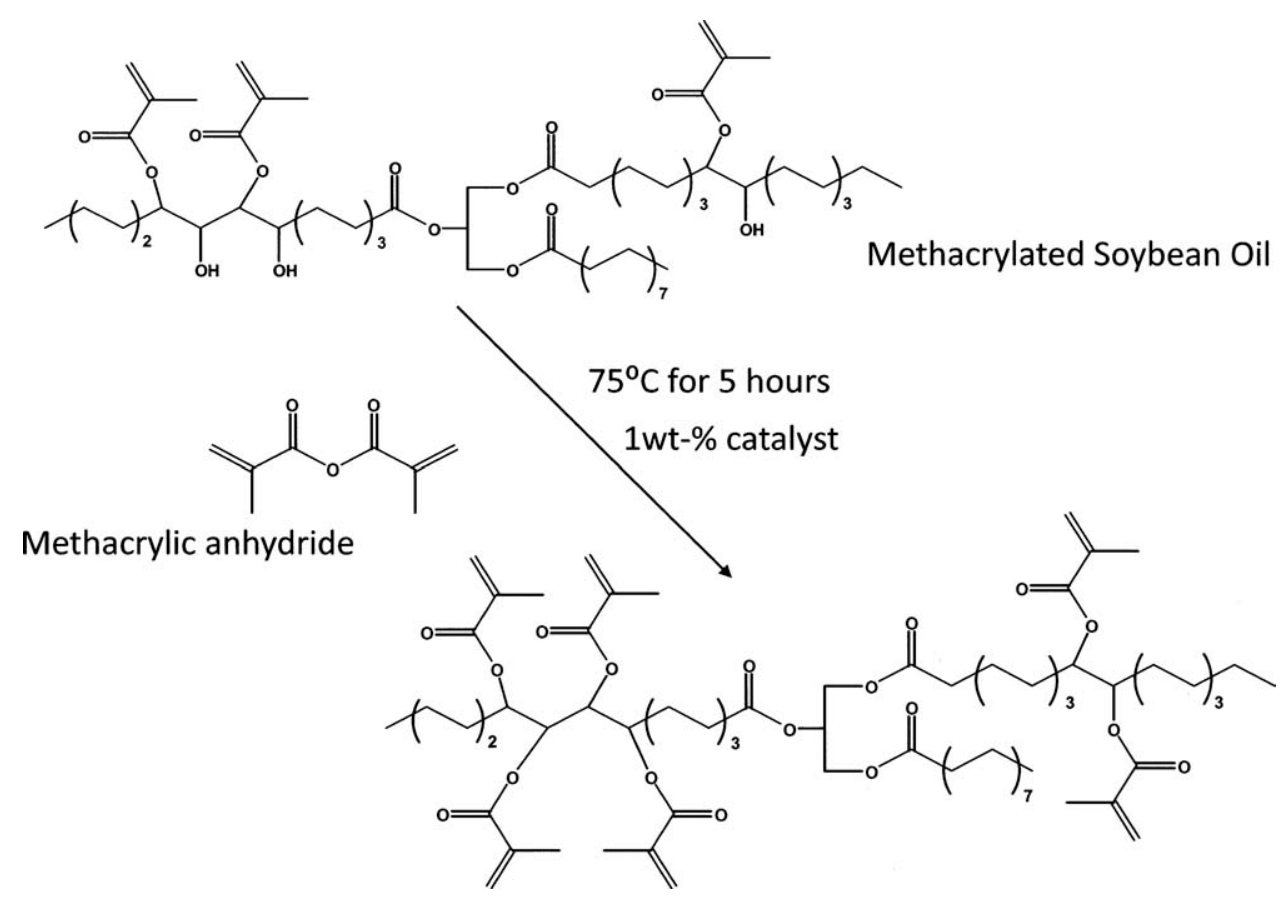

Figure 1 Chemical modification of methacrylated soybean oil (MSO) to give methacrylic anhydride-modified soybean oil (MMSO).

polypropylene. Various treatments can be done to these natural fibers to improve their wettability and consequently improve the fiber-matrix adhesion in the resulting composite. Many authors have done extensive work on natural fiber treatment. ${ }^{21-23}$

Lyocell is a regenerated cellulose fiber derived from bleached wood pulp. Lyocell is obtained by a solvent spinning technique, using $N$-methylmorpholine $\mathrm{N}$-oxide as the solvent. The spinning process is simpler and more environmentally sound than the Viscose spinning process, as it uses a solvent that is less toxic than the carbon disulfide used in the Viscose process, it can also be recycled in the manufacturing process. The regenerated cellulose fibers are of interest in structural composites, as they represent chemically pure cellulose fibers with an even quality and performance that cannot be achieved with mechanically treated natural fibers such as flax and hemp.

A hybrid biobased composite is a combination of the individual characteristics of at least two different types of natural fiber reinforcements in a single renewable matrix. The properties of hybrid composites are a weighed sum of the individual components, but there may be a more favorable balance between the inherent advantages and disadvantages. ${ }^{24}$ This means that the attributes of one type of fiber can complement ones lacking in the other. ${ }^{24}$ As a result, a balance in cost and performance can be achieved through proper material design.

In this study, woven jute fabrics and carded Lyocell fiber mat were used as reinforcements in the methacrylic anhydride-modified soybean oil (MMSO) thermoset, and the properties of the composites were analyzed by tensile and flexural testing, testing of impact resistance, and dynamic mechanical thermal analysis (DMTA). Microstructural analysis was done with scanning electron microscopy (SEM).

\section{EXPERIMENTAL}

\section{Materials}

MMSO was used as matrix in the preparation of composite. The synthetic pathway for chemical modification of the MMSO is shown in Figure 1. The matrix resin was synthesized according to a method published earlier. ${ }^{25}$ Three different types of jute and carded Lyocell reinforcements were used in the preparation of composite: Lyocell fiber (Tencel Lenzing Lyocell, $1.7 \mathrm{dtex}, 30 \mathrm{~mm}$ cut length) was supplied by Lenzing AG, Business Development and Innovation Textiles (Lenzing, Austria). The Lyocell fiber was carded and needled to obtain a nonwoven mat. Biaxial-woven jute fabrics with surface weights of 240, 300, and $100 \mathrm{~g} / \mathrm{m}^{2}$ were all supplied by HP Johannesson Trading AB (Svalöv, Sweden; Fig. 2 and Table I). The free radical initiator, tert-butylperoxybenzoate was supplied by Aldrich Chemical Company (Wyoming, IL).

\section{Carding and needling of the Lyocell fiber}

The carding of the cellulose fiber was done with a cylindrical cross-lap machine supplied by Cormatex (Prato, Italy). The cellulose fibers were separated 


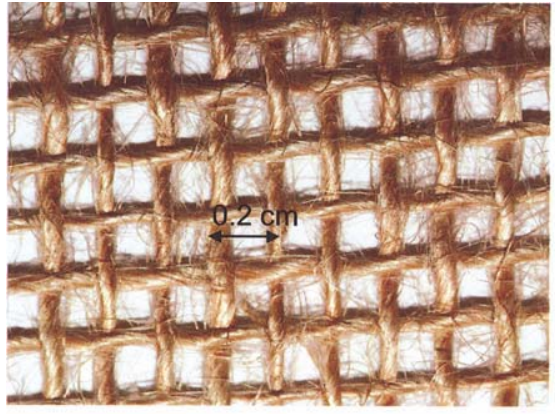

a) Woven fabric, W1

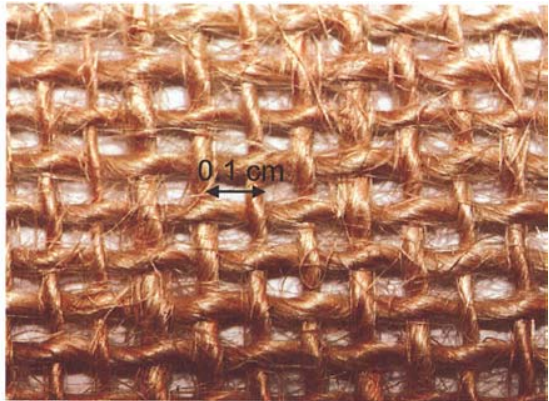

b) Woven fabric, W2

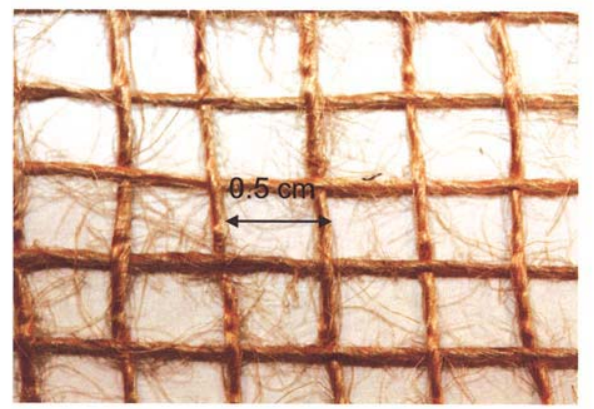

c) Woven fabric, W3

Figure 2 Jute woven fabrics. [Color figure can be viewed in the online issue, which is available at wileyonlinelibrary.com.]

manually and fed into the carding machine. The frequency of the trolley was $40 \mathrm{~Hz}$, which was equivalent to $7.5 \mathrm{~m} / \mathrm{min}$ at the outlet. The needling was done at a frequency of $200 \mathrm{cp} / \mathrm{min}$ and the feeding rate was $1.5 \mathrm{~m} / \mathrm{min}$, while the depth of the needle was $8 \mathrm{~mm}$. The needling machine was supplied by Certec (Sourcieux-les-Mines, France)

Needle penetration depth and frequency contributed to entanglement of the fiber. The frequency is related to the feeding speed: the more the needling, the stiffer the material obtained. In this case, the needling was done three times. The surface weight of the carded Lyocell mat was $525 \mathrm{~g} / \mathrm{m}^{2}$.

\section{Composite preparations}

The jute fibers were washed with $4 \%$ sodium hydroxide solution for $1 \mathrm{~h}$ and dried overnight; they were post-treated by heating at $105^{\circ} \mathrm{C}$ for $1 \mathrm{~h}$. As the natural fibers bear hydroxyl groups from cellulose and lignin, they are amenable to modification. The hydroxyl groups may be involved in the hydrogen bonding in the cellulose molecules, thereby reducing the activity toward the matrix. ${ }^{26}$ Chemical modifications may activate these groups or introduce new moieties that can effectively interlock with the matrix. $^{26}$ The Lyocell fiber was not washed. The matrix used was MMSO blended with 2 wt \% tert-butylperoxybenzoate as free radical initiator.
Composites and hybrid composites were prepared for the purpose of comparison. Composite laminates were made by stacking sheets of fiber mats as a preform, and resin impregnation was done by hand spraying. The prepreg was then inserted in a mold and compression molded at $160^{\circ} \mathrm{C}$ for $5 \mathrm{~min}$ using a pressure of 40 bar to get an approximate thickness of 3.5-3.7 $\mathrm{mm}$ for the composites and a thickness of 3.9-4.3 for the hybrid composites. The hybrid composites were made by sandwiching plies of Lyocell fiber in between the jute fibers. The jute/Lyocell ratio was maintained at approximately $60: 40$ by weight (see Table II) and compression molded as explained earlier. The direction of the carding was taken to be the direction of the fiber in the case of the Lyocell fiber, whereas there was no specific fiber direction in the case of the jute woven fabrics because all the samples are biaxial. The hot press was supplied by Rondol Technology (Staffordshire, UK). The fiber/resin ratio was about $60: 40 \mathrm{wt} \%$ in all cases.

TABLE I

Characterization of Jute Fabric Reinforcements

\begin{tabular}{lcccc}
\hline Fibers & $\begin{array}{c}\text { Yarn per } \\
10 \mathrm{~cm} \\
\text { (weft) }\end{array}$ & $\begin{array}{c}\text { Yarn per } \\
10 \mathrm{~cm} \\
\text { (warp) }\end{array}$ & $\begin{array}{c}\text { Twist (turns } \\
\text { per inch) }\end{array}$ & $\begin{array}{c}\text { Surface } \\
\text { weight } \\
\left(\mathrm{g} / \mathrm{m}^{2}\right)\end{array}$ \\
\hline W1 & 32 & 40 & $4-5$ & 240 \\
W2 & 46 & 50 & $4-5$ & 300 \\
W3 & 15 & 17.5 & $4-5$ & 100 \\
\hline
\end{tabular}


TABLE II

Composite Laminate Compositions

\begin{tabular}{lcccc}
\hline Composites & $\begin{array}{c}\text { Number } \\
\text { of jute } \\
\text { plies }\end{array}$ & $\begin{array}{c}\text { Number } \\
\text { of Lyocell } \\
\text { plies }\end{array}$ & $\begin{array}{c}\text { Total } \\
\text { number } \\
\text { of plies }\end{array}$ & $\begin{array}{c}\text { Weight } \\
\text { of } \\
\text { preforms (g) }\end{array}$ \\
\hline W1 & 14 & 0 & 14 & 82 \\
W2 & 10 & 0 & 10 & 80 \\
W3 & 27 & 0 & 27 & 81 \\
L & 0 & 6 & 6 & 81 \\
W1L (hybrid) & 8 & 3 & 11 & 82 \\
W2L (hybrid) & 5 & 3 & 8 & 80 \\
W3L (hybrid) & 18 & 3 & 21 & 82 \\
\hline
\end{tabular}

Percentage weight (wt \%) jute/Lyocell was 60/40 and the fiber-matrix ratio was approximately $60: 40$.

Composites reinforced with woven fabric of $240 \mathrm{~g} / \mathrm{m}^{2}$ surface weight were denoted W1 (see Table I), those with woven fabric of $300 \mathrm{~g} / \mathrm{m}^{2}$ surface weight were denoted W2, those with woven fabric of $100 \mathrm{~g} / \mathrm{m}^{2}$ surface weight were denoted $\mathrm{W} 3$, and the Lyocell-reinforced composite was denoted L. The hybrid composites from the woven fabric/Lyocell were denoted as follows: W1L, W2L, and W3L.

\section{Characterization}

Mechanical characterizations of the composites were done by tensile, impact, and flexural testing. To obtain high-quality test specimens, cutting of all specimens was done with a laser cutting machine. This machine was a Laserpro Spirit (50-W sealed $\mathrm{CO}_{2}$, DC servo control, and $860 \times 460 \mathrm{~mm}^{2}$ work area). The Lyocell composite specimens were all cut in the carding direction.

The tensile testing was performed according to the ISO 527 standard test method for fiber-reinforced plastic composites, with a universal testing machine (H10KT; maximum capacity $10 \mathrm{kN}$; Tinius Olsen, Salford, UK). For each composite laminate, 10 specimens were analyzed.

The flexural testing was performed according to ISO 14125, using the same testing machine. At least seven specimens of every material were tested.

Impact testing was done on the composite laminates to determine the Charpy impact strength of the unnotched specimens. This was evaluated in accordance with ISO 179 using a Zwick test instrument. Ten specimens in total were tested to determine the mean impact resistance. The samples were tested edgewise.

The time-temperature dependency of the mechanical properties was determined by DMTA, using a Q-series TA instrument dual cantilever supplied by Waters LLC (Newcastle, DE). The temperature range was from $30^{\circ} \mathrm{C}$ to $150^{\circ} \mathrm{C}$, and the frequency was $1 \mathrm{~Hz}$.

SEM analysis was performed on the tensilefractured specimens. Gold coating of the fractured specimens was done with a sputter coater (S150B) in argon gas and at 3 mbar. The specimens were later analyzed with DSM 940A equipment, supplied by Blue Lion Biotech LLC (Snoqualmie, WA). The equipment was run at $2.0 \mathrm{kV}, 8.0 \times 500 \mathrm{~mm}^{2}$.

\section{RESULTS AND DISCUSSION}

\section{Tensile properties}

The Lyocell fiber-reinforced composite L was used for comparison. The tensile strength of this composite was found to be almost double when compared with those of the other composites (see Fig. 3). Although the Lyocell is nonwoven, the three times needling of the carded mat may have imparted higher mechanical properties to the fiber which then gave better tensile strength to the resulting composite. All three jute fabrics had plain-weave architecture but the major difference was the distance between the adjacent roving wefts and warps [Fig. $2(\mathrm{a}-\mathrm{c})]$. The difference could be seen in the tensile strengths; however, because they had different strengths-which may have been a result of the weft and warp distances. The fiber weight percentage was the same for all composites made. Although woven fabrics gain integrity from interlacing of warp and weft, interlacing induces waviness of tows, which in turn imparts crimp-and this may affect the mechanical properties of the composite. Interlace points have been identified as one of the weakest points in most woven fabric composite systems, and interlace points are higher in the case of plain-weave architecture. This could lead to the presence of voids and fiber distortion at the interlace gap. ${ }^{24}$ The Lyocell composite (L) had a superior tensile strength of about $144 \mathrm{MPa}$, which indicated that this composite was the toughest and strongest (see Fig. 3). The direction of carding was taken to be the fiber direction in the case of the Lyocell fiber, and this might also have contributed to the better tensile properties.

However, there was a huge effect of Lyocell hybridization on all the jute composites; for instance,

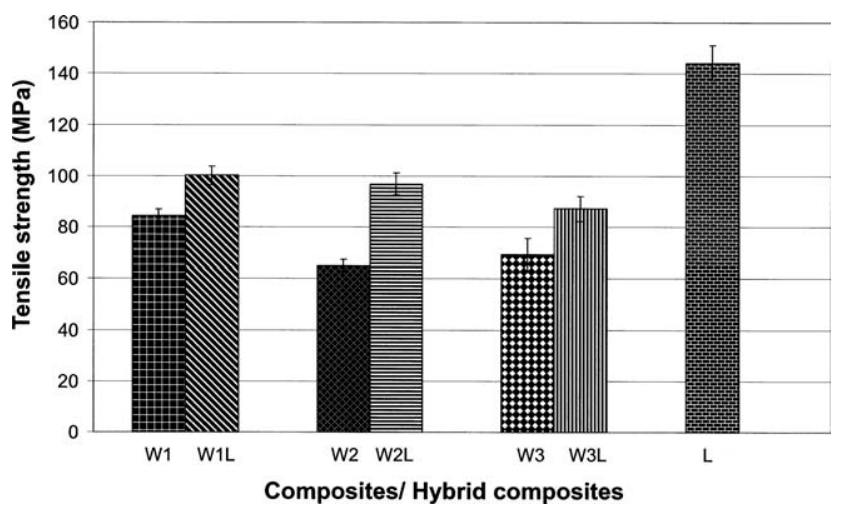

Figure 3 Tensile strength of the jute and Lyocell composites compared with the jute/Lyocell hybrid composites. 


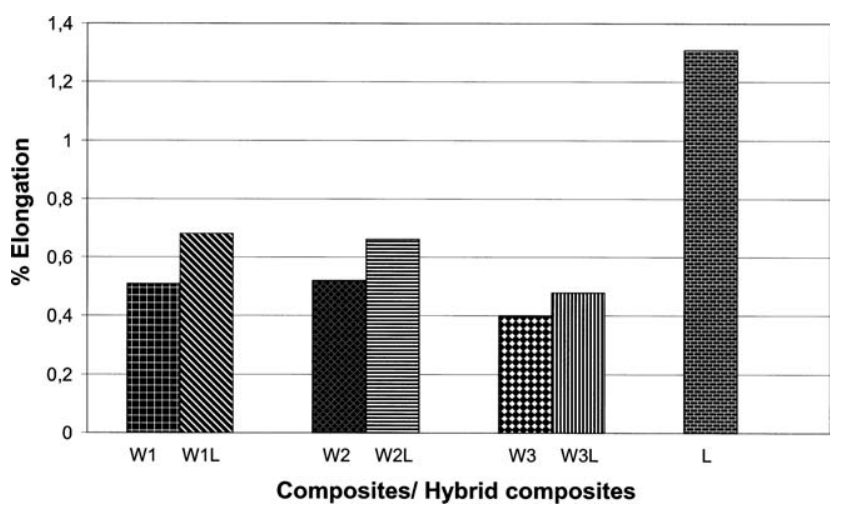

Figure 4 Percentage elongation of the composites and the hybrid composites.

the tensile strength of the hybrid composites (W1L, W2L, and W3L) was increased by $19 \%, 48 \%$, and $26 \%$, respectively (Fig. 3). The improvement in tensile properties was conspicuous in the hybridization with the woven fabrics. This may be due to the morphology of the Lyocell fiber.

The percentage elongation (Fig. 4) for the jute fiber-reinforced composites was about $0.5 \%$ on the average. The percentage elongation for the Lyocellreinforced composite (L) was about $1.3 \%$; this was to be expected, due to the morphology of the regenerated cellulose fiber. This is evident in the higher tensile and flexural strengths and also in the high impact resistance. The hybrid composites showed improvement in elongation properties due to the effect of the Lyocell fiber. However, Lyocell fiber imparts toughness to the composites.

In this work, equal fiber weight percentage was used in all cases to achieve reproducibility (see Table II). The tensile modulus of the composites was relatively high (between 14 and 19 GPa; Fig. 5) and when the standard deviation is taken into consideration, one can say that all the composites had almost equal stiffness.

However, hybridization of the woven fabric W2 $\left(300 \mathrm{~g} / \mathrm{m}^{2}\right)$ with Lyocell fiber showed an appreciable

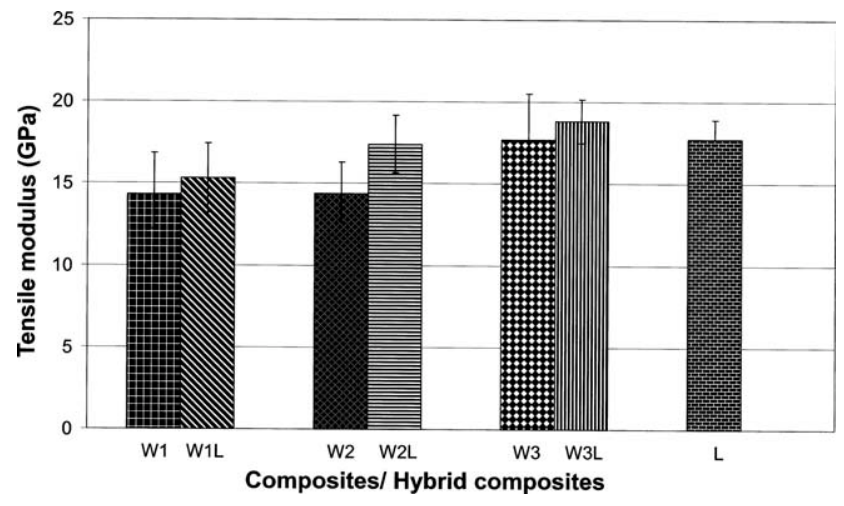

Figure 5 Tensile moduli of the jute and Lyocell composites compared with those of the jute/Lyocell hybrid composites.

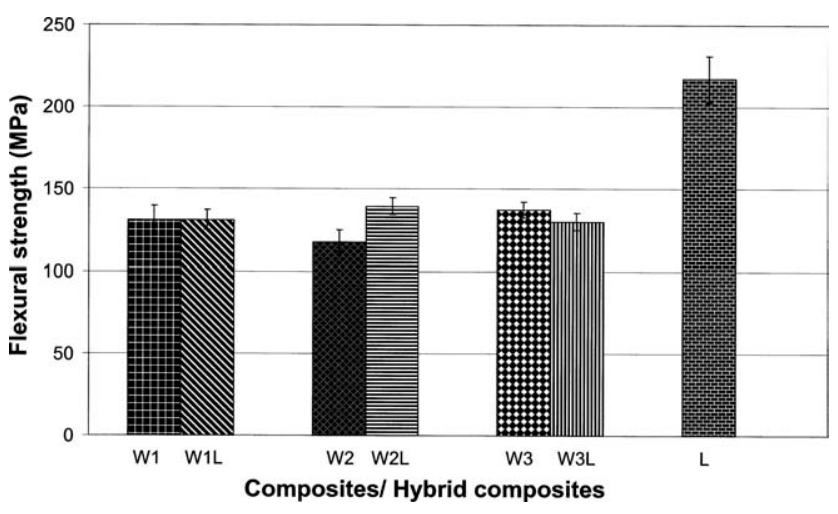

Figure 6 Flexural strength comparison of the composites and the hybrid composites.

increase in tensile modulus from 14 to $17 \mathrm{GPa}$ (see composite W2L in Fig. 5). Hybridization of Lyocell fiber with woven jute fabrics could impart toughness to the manufactured composites.

\section{Flexural properties}

Figure 6 shows the flexural strength of the composites. The Lyocell-reinforced composite L showed the highest flexural strength of about $217 \mathrm{MPa}$. The hybrid Lyocell/jute fiber composite W2L showed increased flexural strength but the effect of hybridization was negligible in composites W1L and W3L (Fig. 6). Misalignment of fibers usually occurs in woven fabrics, especially when there is appreciable distance between the adjacent weft and warp, and this could be the possible reason for the drop in flexural strength in composite W3L.

The Lyocell-reinforced composite had the highest flexural modulus of about 13 GPa (Fig. 7), but hybridization of Lyocell fiber with other jute fibers had a negligible effect on the flexural modulus of the resulting hybrid composites. When the individual hybrid composites (W1L, W2L, and W3L) were compared, however, the thickness of the external plies (see Table II) may have contributed to the

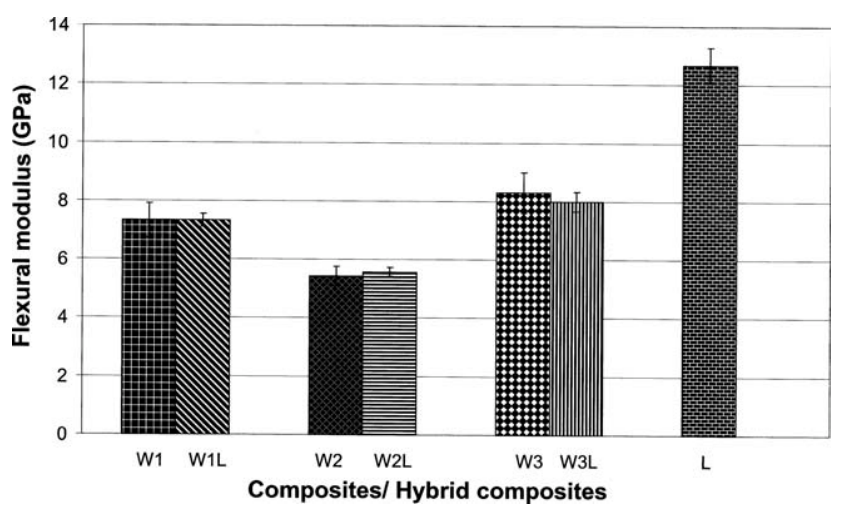

Figure 7 Flexural modulus comparison of the composites and the hybrid composites. 


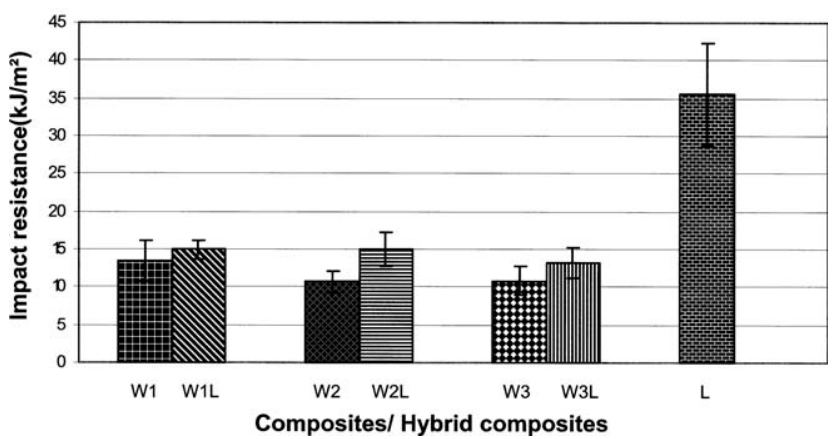

Figure 8 Impact resistance of both the composites and the hybrid composite.

flexural modulus of each composite. Hybrid composites W3L, W1L, and W2L had thicker outer plies in that order, and thus flexural modulus of 8,7 , and $6 \mathrm{GPa}$, respectively.

\section{Impact resistance}

Figure 8 represents the Charpy impact resistance (energy absorbed/cross-sectional area). The jute composites (W1, W2, and W3) showed relatively low impact resistance between 11 and $13 \mathrm{~kJ} / \mathrm{m}^{2}$, which could be attributed to good fiber-matrix adhesion. Higher fiber-matrix adhesion resulted in shorter average pull-out lengths, and therefore caused lower impact resistance or strength. The results from the flexural tests showed higher flexural strengths for the jute composites of between 120 and $137 \mathrm{MPa}$ and flexural moduli of between 5 and $8.5 \mathrm{GPa}$.

The matrix used in the preparation of composite (MMSO) has a higher cross-linking density due to a higher number of reactive double bonds in the molecular structure. The neat MMSO resin is also very brittle.

The Lyocell composite (L) had the highest impact resistance $\left(36 \mathrm{~kJ} / \mathrm{m}^{2}\right.$; Fig. 8$)$, which indicated a longer fiber pull-out length, and this could be due to the structural and morphological nature of the Lyocell fiber (regenerated cellulose fiber). The hybridization of the jute fibers with Lyocell fiber increased the impact resistance of the composites slightly to between 14 and $15 \mathrm{~kJ} / \mathrm{m}^{2}$ (see composites W1L, W2L, and W3L in Fig. 8).

\section{Dynamic mechanical thermal analysis}

Storage modulus is a measure of the elastic response of a material, and in this study, the Lyocell composite L showed the highest storage modulus (Fig. 9). This indicates that it has better elastic properties than the other composites. Loss modulus is a measure of the viscous response of a material. The Lyocell composite L had the highest loss modulus (Fig. 10). The

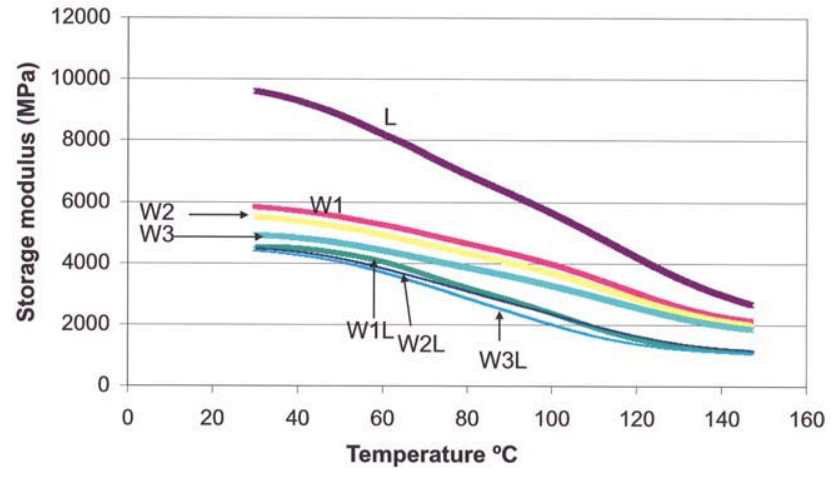

Figure 9 Storage modulus of the various composite and hybrid composite samples obtained from the DMTA. [Color figure can be viewed in the online issue, which is available at wileyonlinelibrary.com.]

results indicate that Lyocell-reinforced composite $\mathrm{L}$ had the best viscoelastic properties of all the manufactured composites and hybrid composites. Viscoelasticity is the ability of a material to exhibit both elastic and viscous behavior. The better properties of the Lyocell composite L could be attributed to its reinforcing effects, which was also supported by the other mechanical analyses.

Hybridization with Lyocell fiber reduced the storage modulus of all the jute composites (Fig. 9), and this could be due to delamination during constant heating and deformation for about $1 \mathrm{~h}$ in the equipment and the possibility of mismatch in the hybrid composite structure. Lyocell fiber and jute fabrics were combined in this case, and a microstructural analysis of a transverse section of the specimen might give a better explanation.

The glass transition temperature can be determined by the $\tan \delta$ curves; see Figure 11 . The $\tan \delta$ peak for the Lyocell composite corresponds to the temperature at $146^{\circ} \mathrm{C}$, while the other jute composites (W1, W2, and W3) have their $T_{\mathrm{g}}$ at about $130^{\circ} \mathrm{C}$. The effect of hybridization reduced the glass transition temperature of all the jute composites,

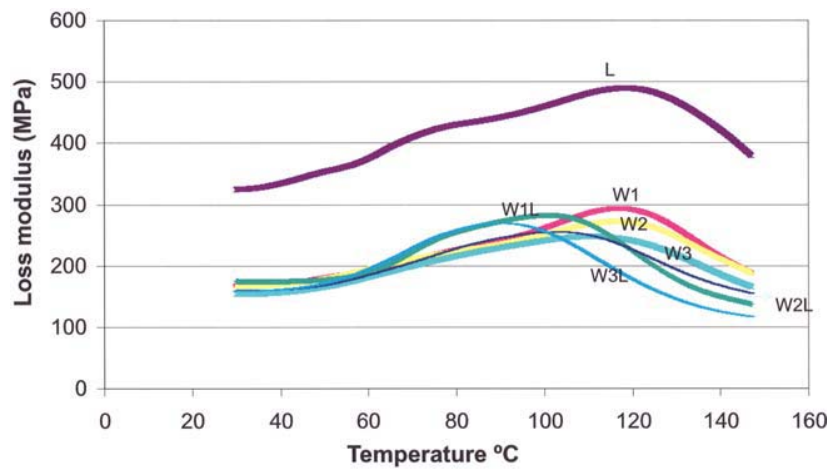

Figure 10 Loss modulus for individual samples obtained from the DMTA. [Color figure can be viewed in the online issue, which is available at wileyonlinelibrary.com.] 


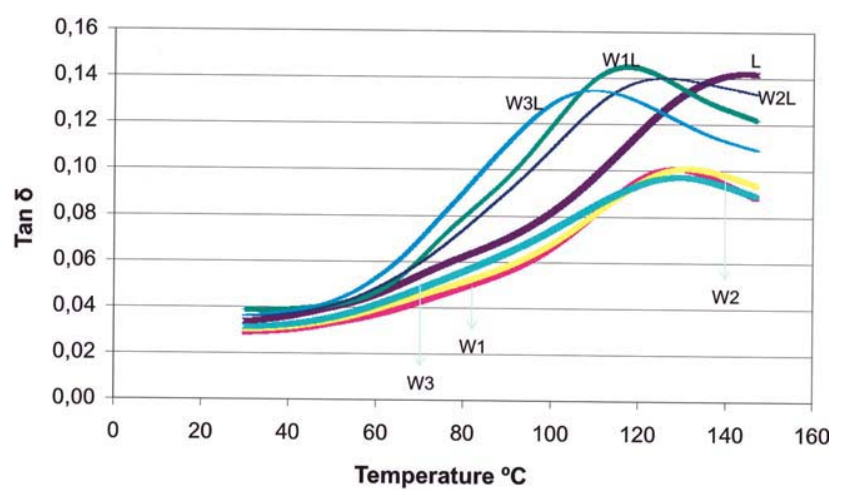

Figure 11 Tan $\delta$ peak of the various composite and hybrid composite samples obtained from the DMTA. [Color figure can be viewed in the online issue, which is available at wileyonlinelibrary.com.]

which might be due to the explanation given in the previous paragraph.

The $T_{\mathrm{g}}$ values obtained in the loss modulus curves (Fig. 10) for all the composites were about $120^{\circ} \mathrm{C}$, while they were between $90^{\circ} \mathrm{C}$ and $100^{\circ} \mathrm{C}$ for the hybrid composites. It can be concluded that the $T_{\mathrm{g}}$ values obtained from the loss modulus curve are lower than those obtained from the $\tan \delta$ curve, which confirms the findings of many authors that the values of $T_{\mathrm{g}}$ from the $\tan \delta$ curve are always exaggerated, whereas those from the loss modulus curve are more reliable. Increase in storage and loss modulus indicates better fiber-matrix adhesion. The ratio of $E^{\prime \prime}$ to $E^{\prime}$ (loss modulus to storage modulus) gives the tangent of the phase angle $\delta ; \tan \delta$ is known as the damping and is a measure of energy dissipation. Such parameters provide quantitative information about the behavior of a material. The storage and loss modulus and the glass transition temperature can be increased by blending the matrix with styrene, but in this study, neat resin was used as a matrix.

\section{Scanning electron microscopy}

Microstructural analysis of the samples was done with SEM. Figure 12(a) shows the microstructure of the tensile-fractured surface of the Lyocell composite L. There was good fiber-matrix adhesion, as it was very difficult to see the fiber pull-out, but there was fiber breakage instead. This indicated that the fiber was well-embedded in the matrix. Fiber pull-out could be seen in composites W1, W2, and W3 [see Fig. 12(b-d)], but the average fiber pull-out length was relatively short, which also indicated that there was good fiber-matrix adhesion but not as good as for the Lyocell composite $\mathrm{L}$.

Figure 13(a-c) shows the hybrid composites that had Lyocell and woven fabrics as reinforcements. The micrographs looked the same, and the effect of hybridization with Lyocell fiber could be observed.

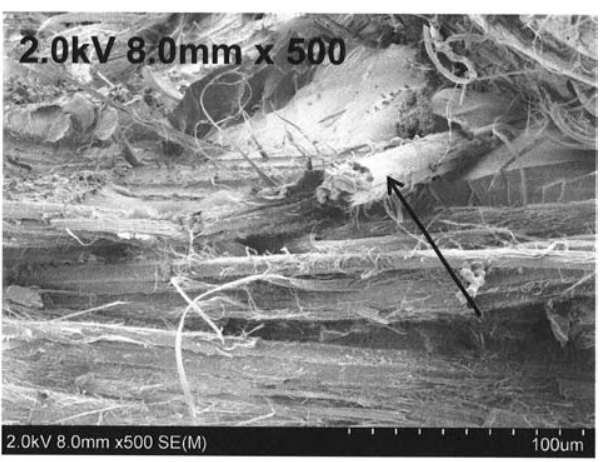

b) W1

a) $L$

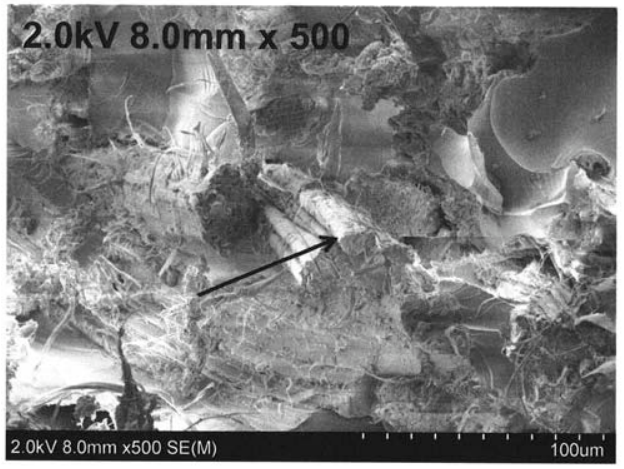

c) W2

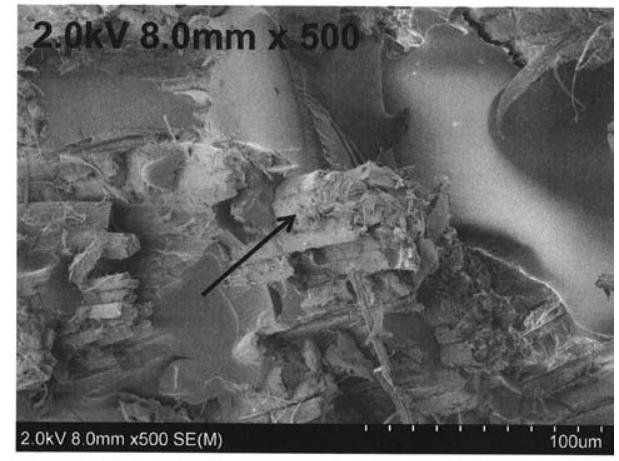

d) W3

Figure 12 Scanning electron micrographs of composites L, W1, W2, and W3. 


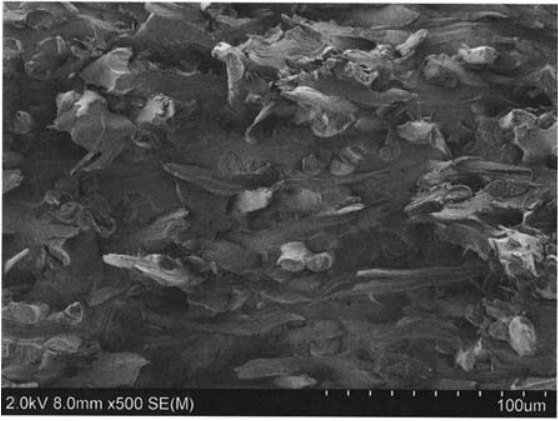

a) W1L

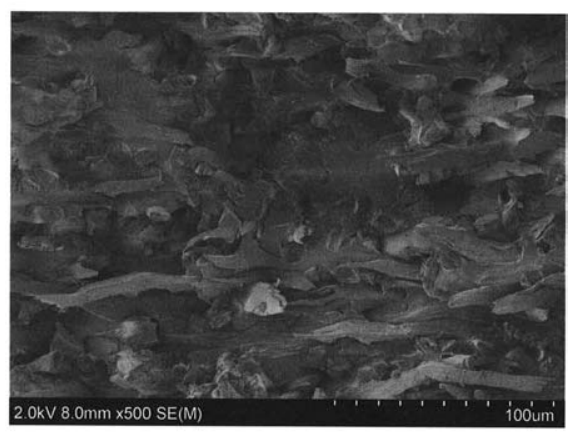

b) W2L

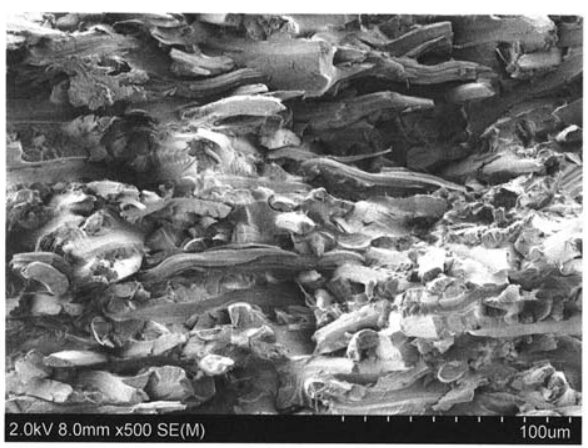

c) W3L

Figure 13 Scanning electron micrographs of composites W1L, W2L, and W3L.

The fiber pull-out that was seen in composites W1, W2, and W3 could not be seen in composites W1L, W2L, and W3L. The tensile properties of the composites and the hybrid composites agreed with the results of the microstructural analysis. Lyocell fiber composite L had a higher tensile strength, which indicated good fiber-matrix adhesion.

\section{CONCLUSIONS}

There were some variations in the mechanical properties, which were due to the different types of reinforcements. In this study, the weave architectures were the same for the woven fabrics but the difference was the distance between adjacent roving wefts and warps, which contributed greatly to the surface weight of the fabric. Although one would have expected composite W2 to have better mechanical properties than the other woven jute composites because the fiber was compact, due to the short distance between the two adjacent roving wefts (about $0.1 \mathrm{~cm}$ ), this was not the case. The other woven jute fabrics had 0.2 and $0.5 \mathrm{~cm}$ between the adjacent wefts and warps, which led to lower surface weight and therefore a higher ply number in the composite. The mechanical properties of composites W1 and W3 were superior to that of W2.

The composites and the hybrid composites had very good mechanical properties. Hybridization with Lyocell fiber increased the overall mechanical properties of the composites but reduced their viscoelastic properties. Although Lyocell offers better performance at low cost, Lyocell fiber cannot replace woven fabric but it can be used as hybrid to complement the properties that are lacking in woven fabrics.

Although the weight ratio of the jute-Lyocell fiber was $60: 40$, the tensile and flexural properties might be improved if the ratio of the Lyocell fiber is increased. Percentage elongation generally improved with inclusion of the Lyocell fiber. To increase toughness in a composite, Lyocell fiber should be used as hybrid.

The authors thank the following people for their assistance in the carding of the Lyocell fiber and also in the impact testing: Anders Bergner and Jan Johansson, Swerea IVF AB, Mölndal, Sweden, and Haike Hilke, University of Borås, Sweden. Lenzing AG, Austria, is gratefully acknowledged for supplying the Lyocell fibers. We also thank Sung-Woo Cho, University of Borås, Sweden, for his help in performing the SEM analysis.

\section{References}

1. Shibata, M.; Takachiyo, K.; Ozawa, K.; Yosomiya, R.; Takeishi, H. J Appl Polym Sci 2002, 85, 129.

2. Luo, S.; Netravali, A. N. Polym Compos 1999, 20, 367.

3. Luo, S.; Netravali, A. N. J Mater Sci 1999, 34, 3709.

4. Shibata, M.; Oyamada, S.; Kobayashi, S.; Yaginuma, D. J Appl Polym Sci 2004, 92, 3857.

5. Graupner, N.; Herrmann, A. S.; Müssig, J. Compos Part A 2009, 40, 810.

6. Takahashi, T.; Hirayama, K.; Teramoto, N.; Shibata, M. J Appl Polym Sci 2008, 108, 1596. 
7. Alix, S.; Morais, S.; Morvan, C.; Lebrun, L. Compos Part A 2008, 39, 1793.

8. Tran, P.; Graiver, D.; Narayan, R. J Appl Polym Sci 2006, 102, 69.

9. John, M. J.; Thomas, S. Carbohydr Polym 2008, 71, 343.

10. Carrillo, F.; Colom, X.; Canavate, X. J Reinforc Plast Compos 2010, 29, 359.

11. Khan, M. A.; Ganster, J.; Fink, H. P. Compos Part A 2009, $40,846$.

12. Li, Y.; Sreekala, M. S.; Jacob, M. Textile Composites Based on Natural Fibers (Chapter 8). Natural Fibre Reinforced Polymer Composites from Macro to Nanoscale, ed. S. Thomas and L.A. Pothan. 2008, Philadelphia, U.S.A: Old City Publishing.

13. Pandita, S. D.; Falconet, D.; Verpoest, I. Compos Sci Technol 2002, 62, 1113 .

14. Bledzki, A. K.; Zhang, W. J Reinforc Plast Compos 2001, 20, 1263.

15. Pothan, L. A.; Mai, Y. W; Thomas, S.; Li, R. K. Y. J Reinforc Plast Compos 2008, 27, 1847.

16. Van de Weyenberg, I.; Chi, T. T.; Vangrimde, B.; Verpoest, I. Compos Part A 2006, 37, 1368.
17. Munikenche, G. T.; Naidu, A. C. B.; Chhaya, R. Compos Part A 1999, 30, 277.

18. Ahmed, K. S.; Vijayarangan, S. J Appl Polym Sci 2007, 104, 2650.

19. Ahmed, K. S.; Vijayarangan, S. J Mater Proces Technol 2008, 207, 330.

20. Wambua, P.; Vangrimde, B.; Lomov, S.; Verpoest, I. Compos Struct 2007, 77, 232.

21. Mohanty, S.; Nayak, S. K. J Reinforc Plast Compos 2006, 25, 1419.

22. Khan, M. A.; Bhattacharia. J Reinforc Plast Compos 2007, $26,617$.

23. Gassan, J.; Bledzki, A. K. Compos Sci Technol 1999, 59, 1303.

24. John, M. J.; Anandjiwala, R. D.; Thomas, S. Old City Publishing, 2009, Chapter 12, pp 315-328.

25. Adekunle, K.; Åkesson, D.; Skrifvars, M. J Appl Polym Sci 2010, 115, 3137.

26. Kalia, S.; Kaith, B. S.; Kaur, I. J Polym Eng Sci 2009, 49, 1253. 